Check for updates

Cite this: Chem. Sci., 2019, 10, 8331

๑ All publication charges for this article have been paid for by the Royal Society of Chemistry

\title{
Catalyst shuttling enabled by a thermoresponsive polymeric ligand: facilitating efficient cross- couplings with continuously recyclable ppm levels of palladium $\dagger$
}

\author{
Erfei Wang and Mao Chen (iD *
}

A polymeric monophosphine ligand WePhos has been synthesized and complexed with palladium(॥) acetate $\left[\mathrm{Pd}(\mathrm{OAc})_{2}\right]$ to generate a thermoresponsive pre-catalyst that can shuttle between water and organic phases, with the change being regulated by temperature. The structure of the polymeric ligand was confirmed with matrix-assisted laser desorption/ionization-time-of-flight (MALDI-TOF) mass spectrometry and size-exclusion chromatography (SEC) analysis, as well as nuclear magnetic resonance (NMR) measurements. This polymeric metal complex enables highly efficient Pd-catalyzed crosscouplings and tandem reactions using 50 to $500 \mathrm{ppm}$ palladium, and this can facilitate reactions that are tolerant to a broad spectrum of (hetero)aryl substrates and functional groups, as demonstrated with 73 examples with up to $99 \%$ isolated yields. Notably, $97 \%$ Pd remained in the aqueous phase after 10 runs of catalyst recycling experiments, as determined via inductively coupled plasma-atomic emission spectrometry (ICP-AES) measurements, indicating highly efficient catalyst transfer. Furthermore, a continuous catalyst recycling approach has been successfully developed based on flow chemistry in combination with the catalyst shuttling behavior, allowing Suzuki-Miyaura couplings to be conducted at gram-scales with as little as $10 \mathrm{ppm}$ Pd loading. Given the significance of transition-metal catalyzed cross-coupling and increasing interest in sustainable chemistry, this work is an important step towards the development of a responsive catalyst, in addition to having high activity, by tuning the structures of the ligands using polymer science.

Received 4th May 2019

Accepted 22nd July 2019

DOI: $10.1039 / \mathrm{c} 9 \mathrm{sc} 02171 \mathrm{j}$

rsc.li/chemical-science

\section{Introduction}

Transition-metal catalyzed cross-coupling reactions have become indispensable tools in organic synthesis. The palladium (Pd)-catalyzed Suzuki-Miyaura (SM) coupling is one of the most heavily used reactions for $\mathrm{C}-\mathrm{C}$ bond formation, ${ }^{1-3}$ and has revolutionized synthetic approaches for pharmaceuticals, ${ }^{4}$ agrochemicals, ${ }^{5}$ polymer materials ${ }^{6}$ and so on. ${ }^{7}$ Notwithstanding its extraordinary advances, the cost of Pd and its separation, as well as the sustainability of this chemistry are almost always concerns when using SM coupling, especially in process research and development; these are also concerns with other precious metal catalyzed reactions..$^{8-10}$ Consequently, methods featuring low Pd loading, ${ }^{11-16}$ recyclable catalysts ${ }^{17,18}$ and aqueous conditions ${ }^{19-21}$ have received increasing attention. For example, Lipshutz and co-workers disclosed that the ppm levels of Pd contained in the iron(III) chloride $\left(\mathrm{FeCl}_{3}\right)$ salt

State Key Laboratory of Molecular Engineering of Polymers, Department of Macromolecular Science, Fudan University, Shanghai 200433, China. E-mail: chenmao@fudan.edu.cn; Web: http://chenmaofudan.wixsite.com/polymao

$\dagger$ Electronic supplementary information (ESI) available. See DOI: $10.1039 / \mathrm{c} 9 \mathrm{sc} 02171 \mathrm{j}$ catalyzed aqueous SM coupling with a dialkylphosphine ligand. ${ }^{11}$ They also reported that SM couplings could be facilitated using amphiphilic molecules in water $\left(\mathrm{H}_{2} \mathrm{O}\right){ }^{12,22,23}$ Based on previous achievements of using electron-rich phosphine ligands to promote SM couplings ${ }^{24-31}$ Carrow and co-workers revealed that a tri(adamantyl)phosphine-Pd complex catalyzed a process with low Pd loadings in an organic solvent. ${ }^{13}$ Whereas polymeric materials loaded with Pd are easily recyclable for homo/heterogeneous SM couplings, ${ }^{32-42}$ in comparison to small molecule catalysts, polymeric catalysts generally exhibit: (a) limited functional group tolerance, (b) decreased reactivity toward deactivated aryl chlorides, and (c) unsatisfactory compatibility with heterocycles. ${ }^{43}$ Furthermore, tandem/ iterative catalysis based on chemoselective SM coupling ${ }^{44-46}$ has rarely been realized with polymeric catalysts.

In this research, a novel polymeric pre-catalyst was synthesized, which was composed of methoxy poly(ethylene glycol) (PEG) linked dicyclohexylphosphine ligand (WePhos) and Pd, which enables a general, efficient and low Pd loading SM coupling via a rapid catalyst transfer between aqueous and toluene phases (Scheme 1). This polymeric complex catalyzed reaction is tolerant of various functional groups as well as 
Previous work:

Small molecular ligand tunable property for highly active catalysis (i.e., monodentate phosphine)

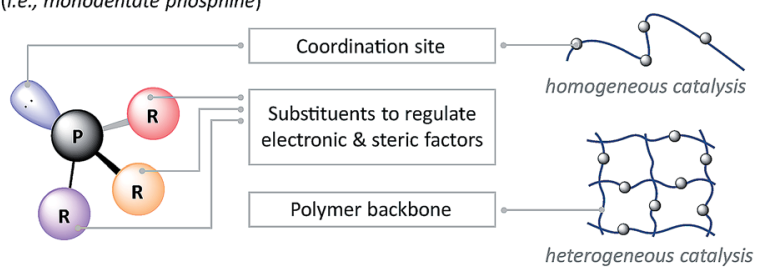

This work: thermoresponsive polymeric complex
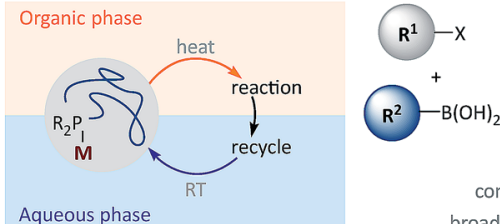

catalyst shuttling

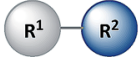

up to $99 \%$ yields

scalable with ppm levels of $\mathrm{Pd}$

continuous-flow catalyst recycling

broad substrate scope (73 examples)

Scheme 1 Ligand design in transition-metal catalyzed cross-coupling

(hetero)aromatic rings, and is realized in tandem coupling with high chemoselectivity. Furthermore, taking advantage of the thermoresponsive catalyst shuttling, a continuous catalystrecycling approach based on flow chemistry was developed to streamline scalable SM couplings using down to $10 \mathrm{ppm}$ of Pd.

The lower critical solution temperature (LCST) behaviour of PEG is known in polymer science, ${ }^{47-50}$ with PEGylated materials exhibiting dramatically decreased solubility in water upon heating above the LCST. It was thought that by introducing a PEGylated phosphine ligand, the corresponding Pd complex would display a thermoresponsive solubility in a biphasic system, thereby promoting a reaction in the organic phase and facilitating catalyst recycling simply by phase separation.

\section{Results and discussion}

At the beginning of the investigation, to confirm and visualize the shuttling effect, a yellow polymeric compound $\mathbf{1}$ was synthesized with $\mathrm{PEG}_{5000}$ (number average molecular weight, $M_{\mathrm{n}} \sim 5000 \mathrm{~g} \mathrm{~mol}^{-1}$ ) and carboxyferrocene (Fig. 1). When $\mathbf{1}$ is dissolved in a mixture of water and toluene at $25{ }^{\circ} \mathrm{C}$, only the water phase shows yellow coloration, however, upon heating to $90{ }^{\circ} \mathrm{C}$, the toluene phase turns yellow within $30 \mathrm{~s}$. The whole process is rapid and completely reversible, clearly exhibiting the

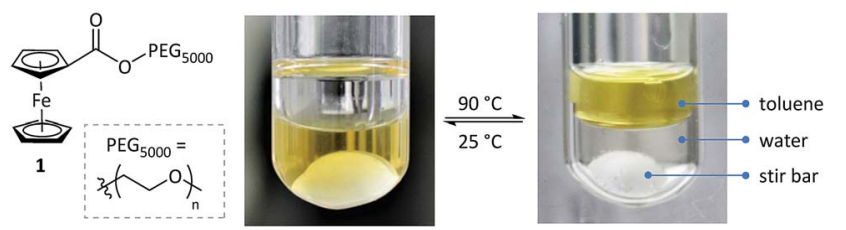

Fig. 1 Optical images of the migration behavior of compound 1 between water and toluene phases in response to temperature.
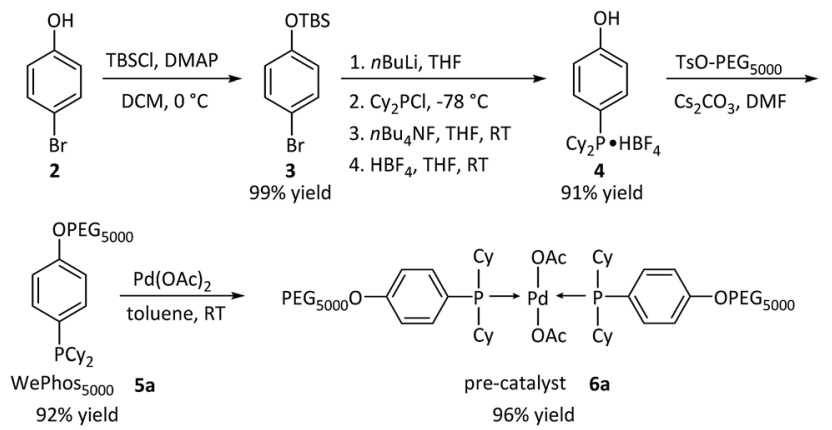

Scheme 2 Synthetic pathway of WePhos 5000 5a and pre-catalyst 6a; $\mathrm{Cy}=$ cyclohexyl group, $\mathrm{AcO}=$ acetate group.

thermoresponsive shuttling of a PEG-supported compound between water and organic phases.

Subsequently, the new ligand WePhos ${ }_{5000} \mathbf{5 a}$ was synthesized using a synthetic route illustrated in Scheme 2. Starting from 4-

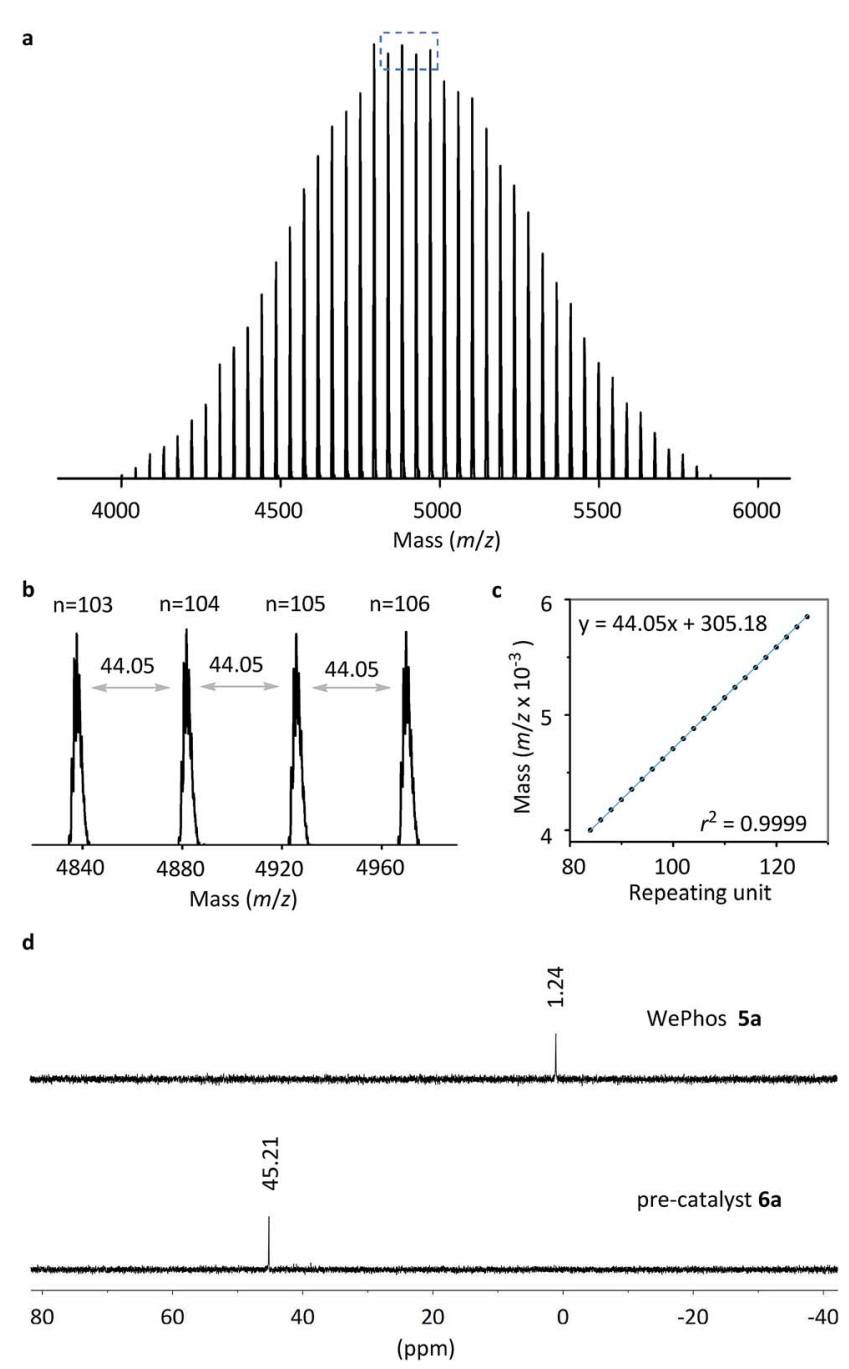

Fig. 2 (a) MALDI-TOF mass spectrum of WePhos 50005 a. (b) Magnified MALDI-TOF mass spectrum of the blue box in (a). (c) $\mathrm{m} / \mathrm{z}$ versus the number of repeating units for the MALDI-TOF mass spectrum of $5 \mathrm{a}$. (d) ${ }^{31} \mathrm{P}-\mathrm{NMR}$ spectra of $5 \mathrm{a}$ and $6 \mathrm{a}$. 
bromophenol 2, a high overall yield of $83 \%$ was obtained for ligand 5a. This compound was air stable, and was characterized using matrix-assisted laser desorption/ionization-time-of-flight (MALDI-TOF) mass spectrometry. As shown in Fig. 2a, a single set of peaks is observed in the MALDI-TOF mass spectrum, and each peak is separated by the molar mass of a single repeating unit in PEG $(\mathrm{m} / z=44.05$, Fig. $2 \mathrm{~b})$. The absolute $m / z$ value was consistent with the calculated molecular weight of 5a. The $y$ intercept of the best-fit trend line of $\mathrm{m} / \mathrm{z}$ versus the number of repeating units indicated the molecular weight of the chain-end group of 5a (Fig. 2c), which was consistent with the expected value. The proton-nuclear magnetic resonance $\left({ }^{1} \mathrm{H}-\mathrm{NMR}\right)$ analysis $^{51}$ also confirmed the chemical structure of WePhos ${ }_{5000}$. Mixing 5a with palladium(II) acetate $\left[\mathrm{Pd}(\mathrm{OAc})_{2}\right]$ in a $2: 1$ ratio, quantitatively generated pre-catalyst $6 \mathbf{6}$. A peak shift from 1.24 to $45.21 \mathrm{ppm}$ in the ${ }^{31} \mathrm{P}-\mathrm{NMR}$ spectra revealed the successful coordination of phosphine to the $\mathrm{Pd}^{\mathrm{II}}$ center (Fig. 2d). ${ }^{52,53}$

Using the same synthetic method, a series of WePhos ligands were prepared using PEGs of different molecular weights $\left(M_{\mathrm{n}} \sim\right.$ $750 \mathrm{~g} \mathrm{~mol}^{-1}$ for $5 \mathbf{b}, M_{\mathrm{n}} \sim 2000 \mathrm{~g} \mathrm{~mol}^{-1}$ for $5 \mathrm{c}, M_{\mathrm{n}} \sim 10000 \mathrm{~g}$ $\mathrm{mol}^{-1}$ for 5d). When these ligands were characterized using size-exclusion chromatography (SEC) (Fig. 3), the SEC profiles showed clear shifts from high to low retention times with no low molar mass tailing (molecular weight distribution, weight average molecular weight/number average molecular weight $\left.\left(M_{\mathrm{w}} / M_{\mathrm{n}}\right)=1.05-1.09\right)$, which indicated the successful preparation of the polymeric ligands with a precise structure.

Next, Pd-complexes of ligands from $5 \mathbf{a}$ to $5 \mathbf{d}$ were used in the SM cross-coupling of bromobenzene and 4-methoxybenzeneboronic acid with potassium carbonate $\left(\mathrm{K}_{2} \mathrm{CO}_{3}\right)$ as the base in water/toluene $(\mathrm{v} / \mathrm{v}=4 / 1)$ at $90{ }^{\circ} \mathrm{C}$. As summarized in Fig. $4 \mathrm{a}$, when the pre-catalyst $6 \mathbf{6}$ was used, the reaction gave the highest yield, in a reaction time of $20 \mathrm{~min}$, determined using gas chromatography (GC, yield $>99 \%) .{ }^{54}$ After cooling down the reaction mixture with $\mathbf{6 a}$ to room temperature (RT), the metalcomplex catalyst was transferred to the aqueous layer and the 4-methoxybiphenyl product was left in the toluene. Using a simple phase separation, the aqueous layer was collected and reused in the next SM cross-coupling reaction. The water phase containing the catalyst was recycled 10 times in this way and

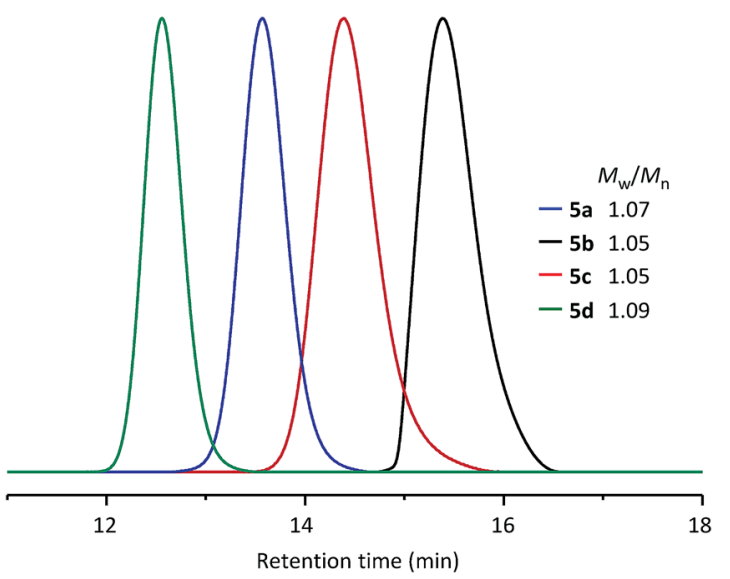

Fig. 3 SEC results for WePhos ligands of different molecular weights.
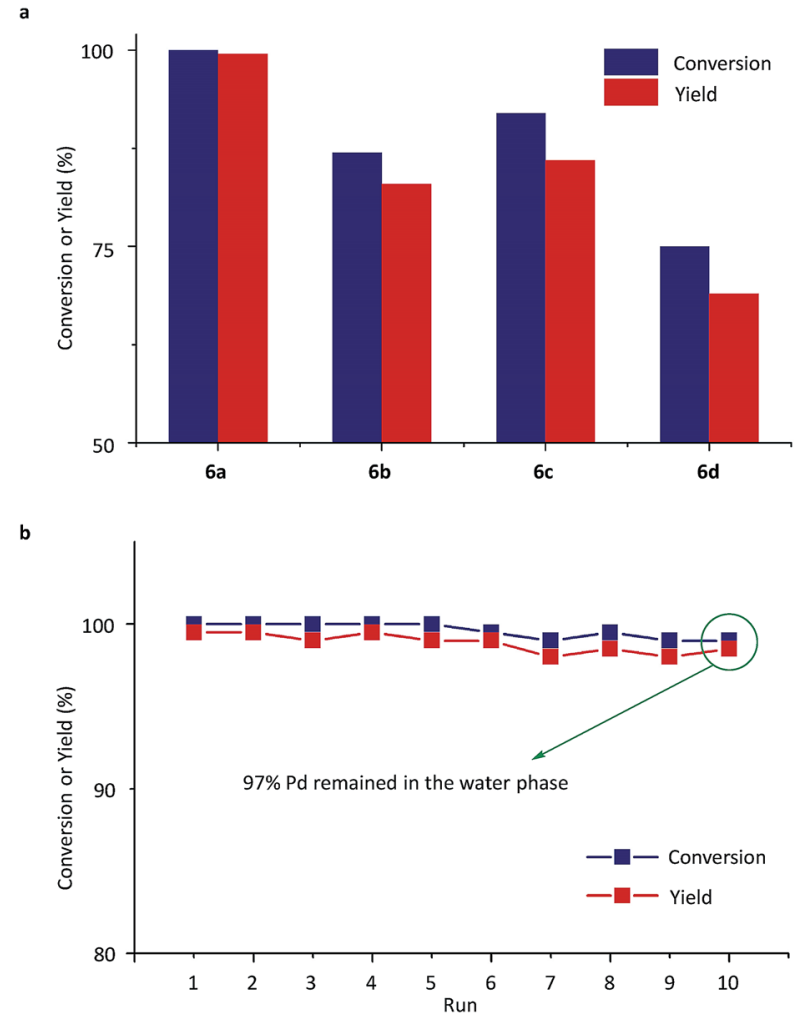

Fig. 4 (a) Conversions and yields of SM cross-couplings between bromobenzene and 4-methoxybenzeneboronic acid with pre-catalysts $6 a, 6 b, 6 c$ and $6 d$. (b) Conversions and yields of target product (4methoxybiphenyl) for the catalyst recycling experiments with $6 a$. Conversions and yields were determined using GC analysis.

there was no clear decrease in GC yields (Fig. 4b). The final aqueous phase was analysed using inductively coupled plasmaatomic emission spectrometry (ICP-AES), which indicated that $97 \%$ of the Pd remained in the aqueous phase, which highlighted the robust catalyst shuttling facilitated by the thermoresponsive polymeric ligand.

With the optimized reaction conditions resolved, the substrate scope of the (hetero)aryl bromides was investigated (Scheme 3). All the substrates underwent complete conversion in $30 \mathrm{~min}$ to $2 \mathrm{~h}$, giving products with good to excellent isolated yields with 50 to $500 \mathrm{ppm}$ of catalyst. The SM reactions catalyzed with polymeric complexes could be successfully carried out with para-, meta-, and ortho-substituted aryl compounds and fused aryl compounds. Electron-deficient, electron-neutral and electron-rich aryl halides were all suitable substrates. The reaction conditions were compatible with a broad scope of functional groups including ester (9), amide (10), aldehyde (11), acetyl (12-14), and nitrile (14), as well as unprotected hydroxyl (13-18), amino (19) and carboxylic acid (20) groups. As is already known, heterocycles are core units of many important pharmaceuticals, organic materials and natural products. $^{55}$ However, heterocycles are likely to coordinate with transition metals, thus representing a challenging class of starting materials for metal-catalyzed reactions with low catalyst dosages. ${ }^{\mathbf{5 6}}$ With this method, a variety of heterocyclic compounds 

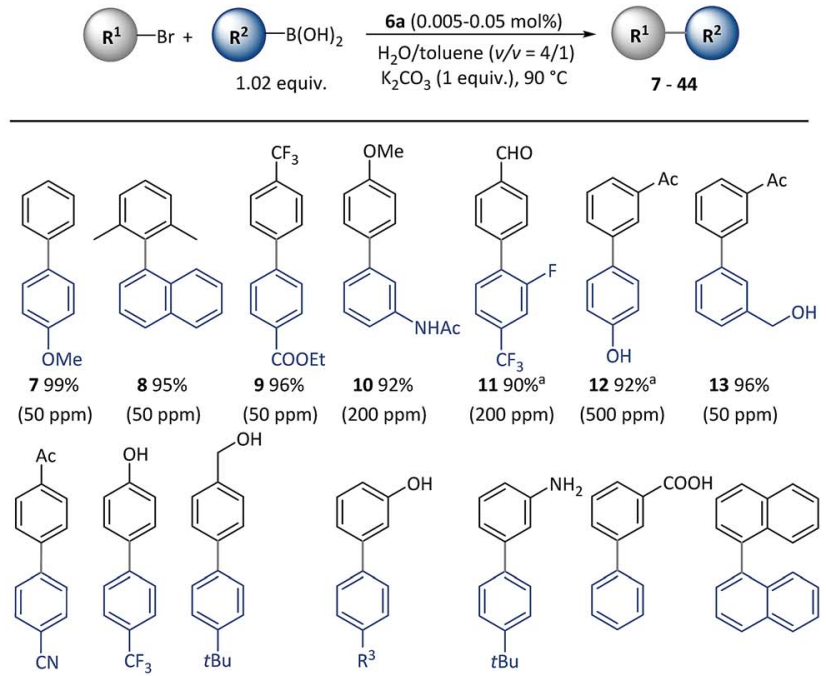

$1493 \%^{\mathrm{a}} \quad 1590 \%^{\mathrm{a}} \quad 1697 \% \quad 17 \mathrm{R}^{3}=t$ Bu $97 \%(500 \mathrm{ppm}) \quad 1997 \% \quad 2095 \% \quad 2197 \%$ $(200 \mathrm{ppm})(500 \mathrm{ppm})(50 \mathrm{ppm}) 18 \mathrm{R}^{3}=\mathrm{CF}_{3} 96 \%(500 \mathrm{ppm})(500 \mathrm{ppm}) \quad(500 \mathrm{ppm}) \quad(50 \mathrm{ppm})$
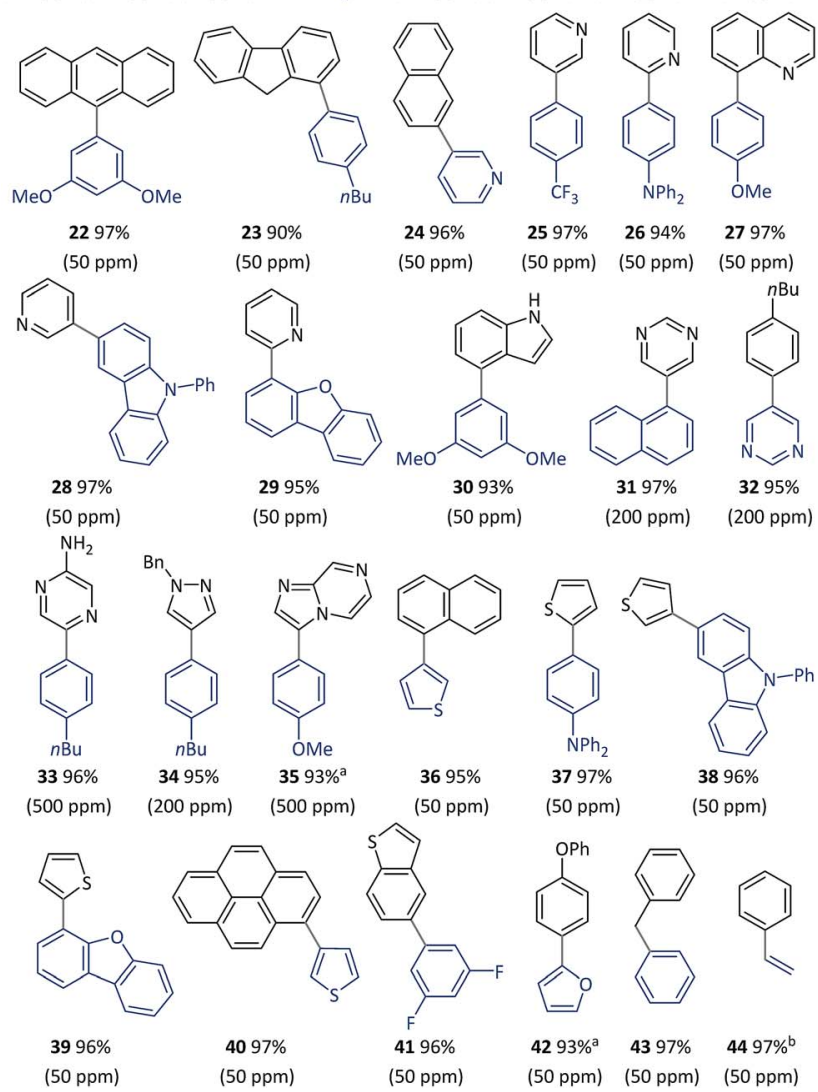

Scheme 3 Cross-coupling of (hetero)aryl bromides using pre-catalyst 6a. Conditions: $\mathrm{R}^{1}-\mathrm{Br}(0.5 \mathrm{mmol}), \mathrm{R}^{2}-\mathrm{B}(\mathrm{OH})_{2}(0.51 \mathrm{mmol}), 6 \mathrm{a}(50-500$ ppm), $\mathrm{K}_{2} \mathrm{CO}_{3}(0.5 \mathrm{mmol}), \mathrm{H}_{2} \mathrm{O}(0.8 \mathrm{~mL})$, toluene $(0.2 \mathrm{~mL}), 90{ }^{\circ} \mathrm{C},(30$ $\mathrm{min})$. Catalyst loadings are listed in parentheses. Isolated yields are based on aryl bromides. ${ }^{\mathrm{a}} 2 \mathrm{~h} .{ }^{\mathrm{b}} \mathrm{R}^{2}$-BPin (boronic acid pinacol ester) was used instead of $\mathrm{R}^{2}-\mathrm{B}(\mathrm{OH})_{2}$.

including pyridine (24-28), quinoline (29), carbazole (27), dibenzofuran (28), indole (30), pyrimidine (31-32), pyrazine (33), pyrazole (34), imidazo[1,2-a]pyrazine (35), thiophene (3640), benzothiophene (41), and furan (42), could be used to generate corresponding products, representing the broadest
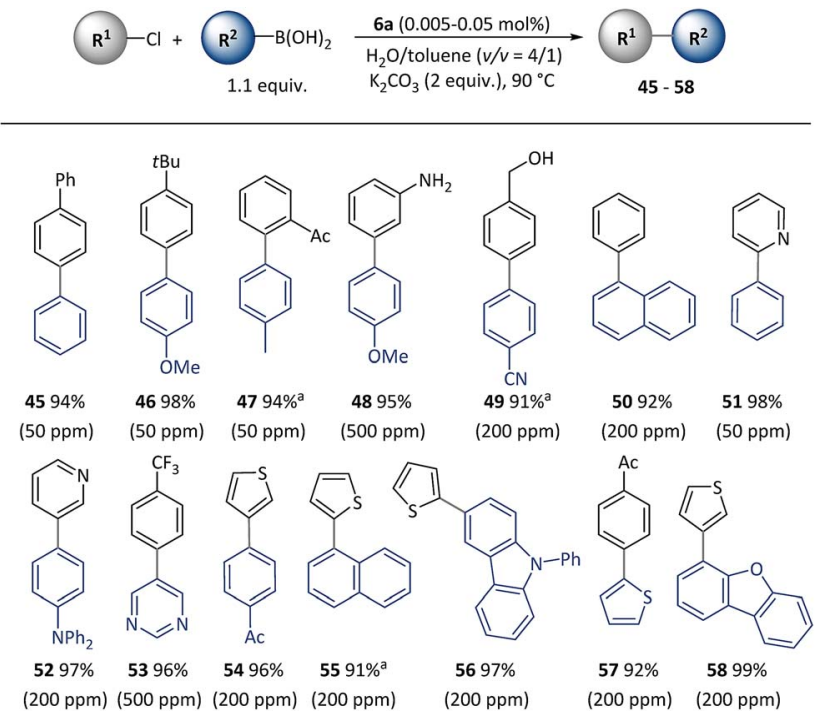

Scheme 4 Cross-coupling of (hetero)aryl chlorides with pre-catalyst 6a. Conditions: $\mathrm{R}^{1}-\mathrm{X}(0.5 \mathrm{mmol}), \mathrm{R}^{2}-\mathrm{B}(\mathrm{OH})_{2}(0.55 \mathrm{mmol}), 6 a(50-500$ ppm), $\mathrm{K}_{2} \mathrm{CO}_{3}(1.0 \mathrm{mmol}), \mathrm{H}_{2} \mathrm{O}(0.8 \mathrm{~mL})$, toluene $(0.2 \mathrm{~mL}), 90{ }^{\circ} \mathrm{C}, 2 \mathrm{~h}$. Catalyst loadings are listed in parentheses. Isolated yields are based on aryl chlorides. ${ }^{\mathrm{a}} 5 \mathrm{~h}$.

substrate scope obtained with a polymeric catalyst as far as is known.

Furthermore, the SM cross-coupling using pre-catalyst 6a was found to be applicable to (hetero)aryl chlorides with a wide substrate scope as shown in Scheme 4. Aryl chlorides with a substituent group at different positions could effectively react with aryl boronic acids (45-48) to give biaryl compounds with yields of 94-98\%. Functional groups [for example, acetyl (47), unprotected amino (48) and hydroxyl (49)] and heterocycles

$$
\mathrm{Cl}-\mathrm{R}^{1}-\mathrm{Br}+\mathrm{R}_{1.02 \text { equiv. }}^{\mathrm{B}(\mathrm{OH})_{2}} \underset{\substack{\mathrm{H}_{2} \mathrm{O} / \text { toluene }(v / v=4 / 1) \\ \mathrm{K}_{2} \mathrm{CO}_{3}(2 \text { equiv. }), 90^{\circ} \mathrm{C}}}{\mathbf{6 a}(0.02-0.05 \mathrm{~mol})} \underset{\mathrm{R}^{1}-\mathrm{R}^{2}}{\mathbf{5 9 - 6 5}}
$$

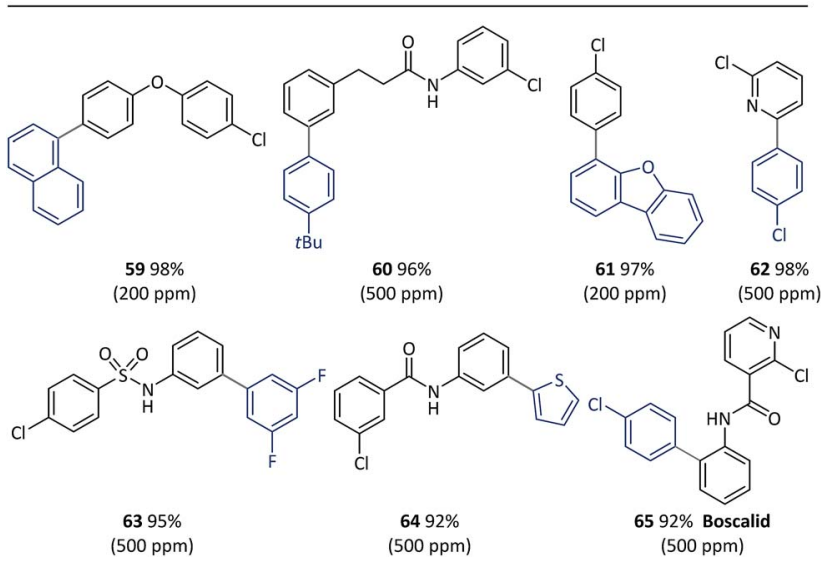

Scheme 5 The chemoselective cross-coupling of conjunctive dihalide compounds using pre-catalyst 6 a. Conditions: $\mathrm{Cl}^{-\mathrm{R}^{1}-\mathrm{Br}}(0.5$ $\mathrm{mmol}), \mathrm{R}^{2}-\mathrm{B}(\mathrm{OH})_{2}(0.51 \mathrm{mmol}), 6 \mathrm{a}(50-500 \mathrm{ppm}), \mathrm{K}_{2} \mathrm{CO}_{3}(1.0 \mathrm{mmol})$, $\mathrm{H}_{2} \mathrm{O}(0.8 \mathrm{~mL})$, toluene $(0.2 \mathrm{~mL}), 90^{\circ} \mathrm{C}, 2 \mathrm{~h}$. Catalyst loadings are listed in parentheses. Isolated yields are based on conjunctive dihalide compounds. 
including pyridine (51-52), pyrimidine (53), thiophene (54-58) and dibenzofuran (58) underwent a smooth reaction with a low (50-500 ppm) catalyst loading, and there were complete conversions in $2-5 \mathrm{~h}$.

Given the different reactivities of $\mathrm{C}-\mathrm{Br}$ and $\mathrm{C}-\mathrm{Cl}$ bonds demonstrated in Pd catalyzed cross-coupling with many small molecule catalysts, the chemical selectivity of polymeric catalyst 6a was next evaluated, as shown in Scheme 5. Excellent selectivity was observed in all the cases examined. A variety of functionalized bi(hetero)aryl were produced with intact aryl chlorides groups (59-65) at above 90\% isolated yields, which could be useful in further metal-catalyzed transformations. It is important to note that the chemoselectivity was not affected by steric or electronic factors with use of the polymeric catalyst.

Tandem SM coupling based on chemoselective reaction facilitated modular and rapid synthesis of diversified molecules for applications such as material screening and drug discovery. ${ }^{4-46,57-59}$ Next, the polymeric catalyst was used in tandem SM coupling based on the different reactivities of electrophiles (Scheme 6). In these reactions, after the first step arylation via $\mathrm{C}-\mathrm{Br}$ bond cleavage, boronic acids were subsequently added into the reaction mixtures without additional catalyst and base. Excellent yields (91-96\%) were obtained for all examples after two-step syntheses in the presence of heterocycles [for example, thiophene (66), pyrimidine (67),
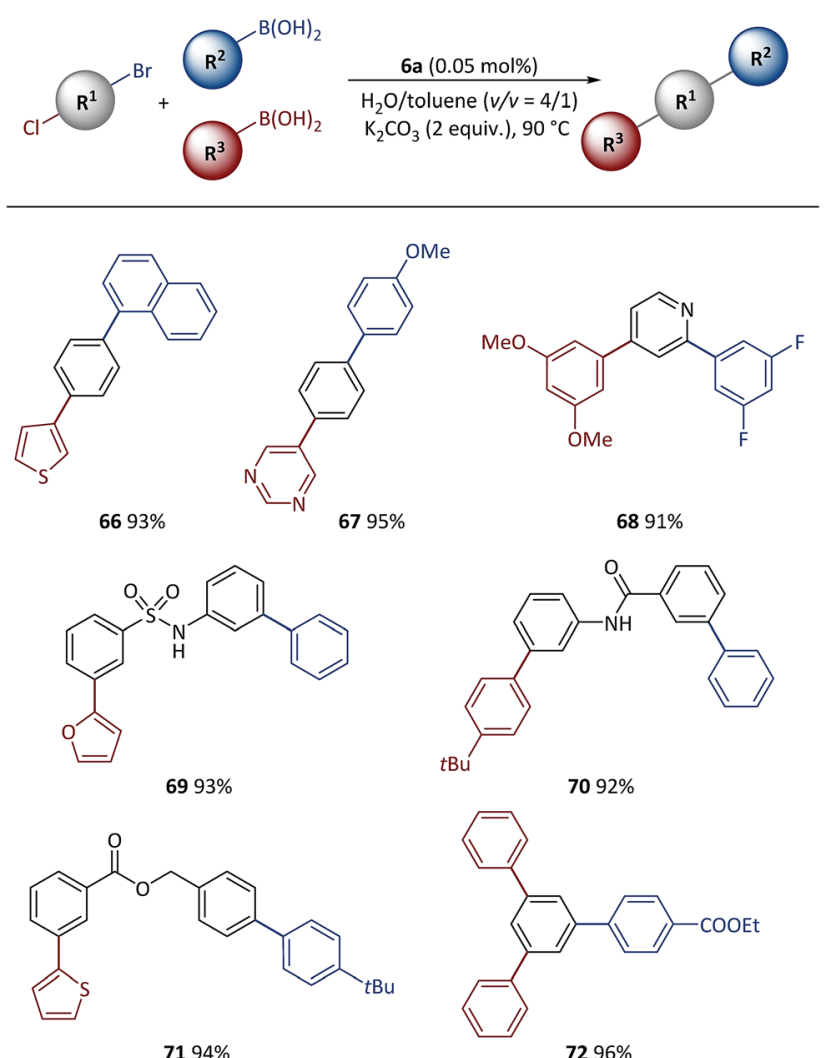

Scheme 6 Tandem SM cross-coupling with pre-catalyst 6a. Conditions: $R^{1}-X(0.5 \mathrm{mmol}), \mathrm{R}^{2}-\mathrm{B}(\mathrm{OH})_{2}(0.51 \mathrm{mmol}), \mathrm{R}^{3}-\mathrm{B}(\mathrm{OH})_{2} \quad(0.55$ $\mathrm{mmol}), 6 \mathrm{a}(500 \mathrm{ppm}), \mathrm{K}_{2} \mathrm{CO}_{3}(1.0 \mathrm{mmol}), \mathrm{H}_{2} \mathrm{O}(0.8 \mathrm{~mL})$, toluene $(0.2$ $\mathrm{mL}), 90{ }^{\circ} \mathrm{C}$. Isolated yields based on conjunctive dihalide compounds.

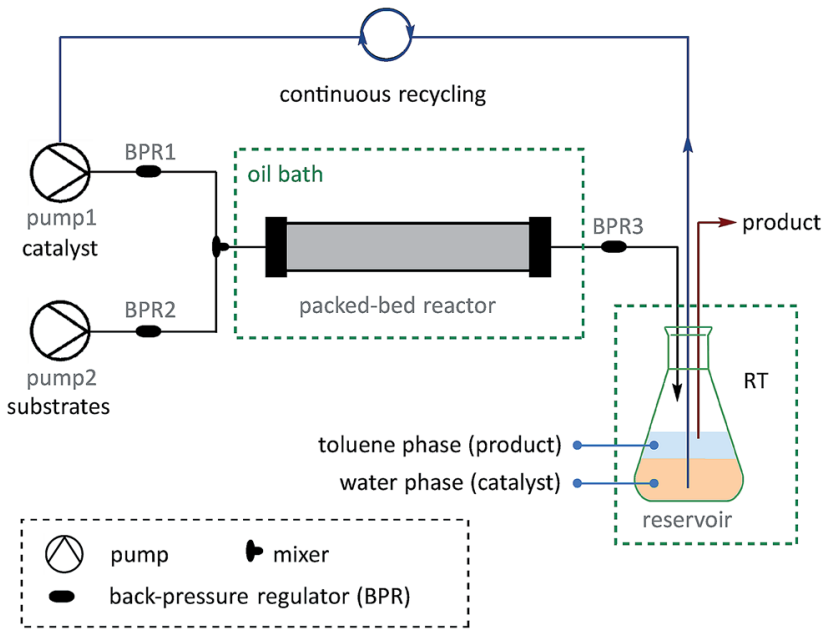

Fig. 5 Set-up for continuous catalyst-recycling synthesis based on flow chemistry.

pyridine (68) and furan (69)] and functional groups [for example, sulfonamide (69), amide (70) and ester (71, 72)], demonstrating the high efficiency achieved with this method.

On the basis of the thermoresponsive catalyst migration, it was anticipated that a continuous-flow synthetic strategy ${ }^{60-67}$ would be practical for scaling-up the SM couplings at ultralow Pd loadings by continuous recycling of catalyst. To realize this idea, a continuous-flow setup was assembled (Fig. 5 and Scheme 7) to synthesize 73, a typical unit with aggregation-induced emission (AIE) behavior, which has been used in high-tech applications such as optoelectronic materials and biomedical sensors. ${ }^{68}$

A solution of pre-catalyst and base in water was mixed with a solution of bromotriphenylethylene and 4-methylphenylboronic acid pinacol ester in toluene, and delivered into a packed bed reactor (packed with stainless steel beads) ${ }^{51}$ submerged in
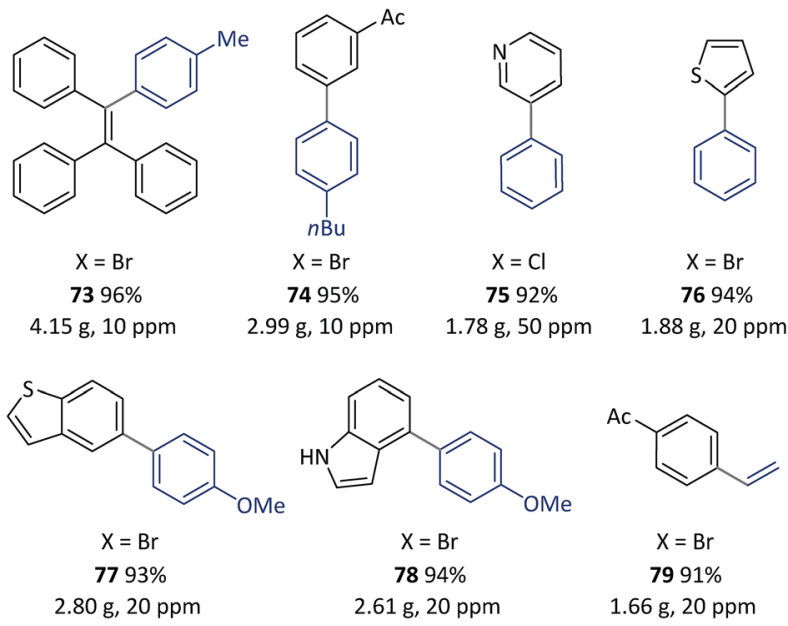

Scheme 7 Examples of SM couplings with the continuous catalystrecycling approach based on flow chemistry. Collections were based on $12.5 \mathrm{mmol}$ aryl halides for all examples. The Pd loadings were calculated according to the molar ratio of $[\mathrm{Pd}] /[$ aryl halide]. See the $\mathrm{ESI} \dagger$ for details of the flow set-up and operations. 
a preheated bath at $110{ }^{\circ} \mathrm{C}$ with a 30 min residence time. After the reaction, the resulting mixture was collected in a flask under a nitrogen atmosphere at RT. The water layer containing the catalyst was continuously extracted using pump 1 and then reinjected into the flow line. In this way, after $8.3 \mathrm{~h}$ of catalyst recycling, $4.15 \mathrm{~g}$ of 73 was isolated from the collected organic layer using only $1.3 \mathrm{mg}$ of pre-catalyst $6 \mathbf{6 a}(13.8 \mu \mathrm{g} \mathrm{Pd})$.

Once this flow technique was available, other bi(hetero)aryl compounds (74-78) and substituted styrene (79) were also successfully synthesized at the gram scale with 10-50 ppm of Pd. Based on the excellent behavior of the continuous catalystrecycling synthesis using flow chemistry, it is believed that a larger scale preparation could be realized by extending the collection time without adding extra catalyst.

\section{Conclusions}

In conclusion, a novel thermoresponsive polymeric catalyst was developed, which can rapidly shuttle between water and organic phases, facilitating a highly efficient SM cross-coupling and tandem reaction with good to excellent isolated yields at ppm levels of catalyst usage. This method allows the preparation of a broad scope of bi(hetero)aryls, and can tolerate various functional groups. Furthermore, in combination with flow chemistry, the catalyst shuttling enables continuous catalyst-recycling, further promoting the scalability and efficiency of cross-coupling using ultralow loadings of palladium. Given the significant influence of transition-metal-catalyzed cross-coupling and increasing interest in sustainable chemistry, it is believed that, based on the strategy presented here, new response modes can be developed by tuning the structures of the ligands using different polymeric species. Also, the compatibility of this method with other metal-catalyzed reactions is under investigation, which would show promise for facilitating other diverse applications.

\section{Conflicts of interest}

There are no conflicts to declare.

\section{Acknowledgements}

This research was financially supported by the National Natural Science Foundation of China (NSFC, no. 21704016), start-up funding from Fudan University, and the National Program for Thousand Young Talents of China.

\section{Notes and references}

1 N. Miyaura and A. Suzuki, Chem. Rev., 1995, 95, 2457-2483. 2 C. C. C. Johansson Seechurn, M. O. Kitching, T. J. Colacot and V. Snieckus, Angew. Chem., Int. Ed., 2012, 51, 5062-5085.

3 A. J. J. Lennox and G. C. Lloyd-Jones, Chem. Soc. Rev., 2014, 43, 412-443.

4 C. Torborg and M. Beller, Adv. Synth. Catal., 2009, 351, 30273043.

5 P. Devendar, R.-Y. Qu, W.-M. Kang, B. He and G.-F. Yang, J. Agric. Food Chem., 2018, 66, 8914-8934.
6 M. J. Robb, S.-Y. Ku and C. J. Hawker, Adv. Mater., 2013, 25, 5686-5700.

7 A. Taheri Kal Koshvandi, M. M. Heravi and T. Momeni, Appl. Organomet. Chem., 2018, 32, e4210.

$8 \mathrm{M}$. Beller and A. Zapf, Handbook of Organopalladium Chemistry for Organic Synthesis, ed. E.-i. Negishi, Wiley, New York, 2002, vol. 1, pp. 1209-1222.

9 B. H. Lipshutz, Chem, 2018, 4, 2004-2007.

10 B. H. Lipshutz, N. A. Isley, J. C. Fennewald and E. D. Slack, Angew. Chem., Int. Ed., 2013, 52, 10952-10958.

11 S. Handa, Y. Wang, F. Gallou and B. H. Lipshutz, Science, 2015, 349, 1087-1091.

12 S. Handa, M. P. Andersson, F. Gallou, J. Reilly and B. H. Lipshutz, Angew. Chem., Int. Ed., 2016, 55, 4914-4918.

13 L. Chen, P. Ren and B. P. Carrow, J. Am. Chem. Soc., 2016, 138, 6392-6395.

14 S. M. Wong, C. M. So, K. H. Chung, C. P. Lau and F. Y. Kwong, Eur. J. Org. Chem., 2012, 2012, 4172-4177.

15 N. E. Leadbeater, V. A. Williams, T. M. Barnard and M. J. Collins, Org. Process Res. Dev., 2006, 10, 833-837.

16 R. K. Arvela, N. E. Leadbeater, M. S. Sangi, V. A. Williams, P. Granados and R. D. Singer, J. Org. Chem., 2005, 70, 161168.

17 Á. Molnár, Chem. Rev., 2011, 111, 2251-2320.

18 W. Wang, L. Cui, P. Sun, L. Shi, C. Yue and F. Li, Chem. Rev., 2018, 118, 9843-9929.

19 T. Kitanosono, K. Masuda, P. Xu and S. Kobayashi, Chem. Rev., 2018, 118, 679-746.

20 B. H. Lipshutz, Current Opinion in Green and Sustainable Chemistry, 2018, 11, 1-8.

21 S. E. Hooshmand, B. Heidari, R. Sedghi and R. S. Varma, Green Chem., 2019, 21, 381-405.

22 E. B. Landstrom, S. Handa, D. H. Aue, F. Gallou and B. H. Lipshutz, Green Chem., 2018, 20, 3436-3443.

23 N. A. Isley, F. Gallou and B. H. Lipshutz, J. Am. Chem. Soc., 2013, 135, 17707-17710.

24 R. Martin and S. L. Buchwald, Acc. Chem. Res., 2008, 41, 1461-1473.

25 S. Harkal, F. Rataboul, A. Zapf, C. Fuhrmann, T. Riermeier, A. Monsees and M. Beller, Adv. Synth. Catal., 2004, 346, 1742-1748.

26 H. Li, C. C. C. Johansson Seechurn and T. J. Colacot, ACS Catal., 2012, 2, 1147-1164.

27 G. C. Fu, Acc. Chem. Res., 2008, 41, 1555-1564.

28 M. Miura, Angew. Chem., Int. Ed., 2004, 43, 2201-2203.

29 U. Christmann and R. Vilar, Angew. Chem., Int. Ed., 2005, 44, 366-374.

30 C. M. So, C. P. Lau and F. Y. Kwong, Angew. Chem., Int. Ed., 2008, 47, 8059-8063.

31 C. Li, D. Chen and W. Tang, Synlett, 2016, 27, 2183-2200.

32 P. Slavik, D. W. Kurka and D. K. Smith, Chem. Sci., 2018, 9, 8673-8681.

33 B. Li, Z. Guan, W. Wang, X. Yang, J. Hu, B. Tan and T. Li, Adv. Mater., 2012, 24, 3390-3395.

34 M. Chtchigrovsky, Y. Lin, K. Ouchaou, M. Chaumontet, M. Robitzer, F. Quignard and F. Taran, Chem. Mater., 2012, 24, 1505-1510. 
35 S. Doherty, J. G. Knight, T. Backhouse, E. Abood, H. Alshaikh, A. R. Clemmet, J. R. Ellison, R. A. Bourne, T. W. Chamberlain, R. Stones, N. J. Warren, I. J. S. Fairlamb and K. R. J. Lovelock, Adv. Synth. Catal., 2018, 360, 3716-3731.

36 R. Shen, W. Zhu, X. Yan, T. Li, Y. Liu, Y. Li, S. Dai and Z.-G. Gu, Chem. Commun., 2019, 55, 822-825.

37 Z. Wang, Y. Yu, Y. X. Zhang, S. Z. Li, H. Qian and Z. Y. Lin, Green Chem., 2015, 17, 413-420.

38 E. Rangel Rangel, E. M. Maya, F. Sánchez, J. G. de la Campa and M. Iglesias, Green Chem., 2015, 17, 466-473.

39 Y. M. A. Yamada, S. M. Sarkar and Y. Uozumi, J. Am. Chem. Soc., 2012, 134, 3190-3198.

40 S. Ogasawara and S. Kato, J. Am. Chem. Soc., 2010, 132, 46084613.

41 Z. Dong and Z. Ye, Adv. Synth. Catal., 2014, 356, 3401-3414.

42 C. Deraedt, L. Salmon and D. Astruc, Adv. Synth. Catal., 2014, 356, 2525-2538.

43 S. Hübner, J. G. de Vries and V. Farina, Adv. Synth. Catal., 2016, 358, 3-25.

44 C. P. Seath, J. W. B. Fyfe, J. J. Molloy and A. J. B. Watson, Angew. Chem., Int. Ed., 2015, 54, 9976-9979.

45 J. W. B. Fyfe, C. P. Seath and A. J. B. Watson, Angew. Chem., Int. Ed., 2014, 53, 12077-12080.

46 L. Xu, S. Ding and P. Li, Angew. Chem., Int. Ed., 2014, 53, 1822-1826.

47 N. Badi, Prog. Polym. Sci., 2017, 66, 54-79.

48 E. E. Dormidontova, Macromolecules, 2004, 37, 7747-7761.

49 J. Seuring and S. Agarwal, Macromol. Rapid Commun., 2012, 33, 1898-1920.

50 E. Bultz, M. Ouchi, K. Nishizawa, M. F. Cunningham and M. Sawamoto, ACS Macro Lett., 2015, 4, 628-631.

51 See the ESI for details. $\dagger$

52 N. C. Bruno, M. T. Tudge and S. L. Buchwald, Chem. Sci., 2013, 4, 916-920.
53 C. S. Wei, G. H. M. Davies, O. Soltani, J. Albrecht, Q. Gao, C. Pathirana, Y. Hsiao, S. Tummala and M. D. Eastgate, Angew. Chem., Int. Ed., 2013, 52, 5822-5826.

54 Lower GC yields with other catalysts could due to: (1) insufficient catalyst concentration in toluene as caused by less efficient UCST behaviour of low-molecular-weight ligands (5b and $\mathbf{5 c}$ ); (2) less efficient reaction caused by the large steric hindrance of the long polymeric chain (5d).

55 J. Alvarez-Builla, J. J. Vaquero and J. Barluenga, Modern Heterocyclic Chemistry, Wiley-VCH, Weinheim, 2011.

56 I. Nakamura and Y. Yamamoto, Chem. Rev., 2004, 104, 21272198.

57 J. Li, A. S. Grillo and M. D. Burke, Acc. Chem. Res., 2015, 48, 2297-2307.

58 E. P. Gillis and M. D. Burke, Aldrichimica Acta, 2009, 42, 17-27.

59 L. Xu, S. Zhang and P. Li, Chem. Soc. Rev., 2015, 44, 88488858.

60 S. V. Ley, D. E. Fitzpatrick, R. J. Ingham and R. M. Myers, Angew. Chem., Int. Ed., 2015, 54, 3449-3464.

61 D. Cambié, C. Bottecchia, N. J. W. Straathof, V. Hessel and T. Noël, Chem. Rev., 2016, 116, 10276-10341.

62 J. A. M. Lummiss, P. D. Morse, R. L. Beingessner and T. F. Jamison, Chem. Rec., 2017, 17, 667-680.

63 F. M. Akwi and P. Watts, Chem. Commun., 2018, 54, 1389413928.

64 D. T. McQuade and P. H. Seeberger, J. Org. Chem., 2013, 78, 6384-6389.

65 M. Chen and S. L. Buchwald, Angew. Chem., Int. Ed., 2013, 52, 11628-11631.

66 M. Chen, S. Ichikawa and S. L. Buchwald, Angew. Chem., Int. Ed., 2015, 54, 263-266.

67 X. Shen, H. Gong, Y. Zhou, Y. Zhao, J. Lin and M. Chen, Chem. Sci., 2018, 9, 1846-1853.

68 J. Mei, Y. Hong, J. W. Y. Lam, A. Qin, Y. Tang and B. Z. Tang, Adv. Mater., 2014, 26, 5429-5479. 